\title{
Host plant resistance against yellow stem borer and rice leaf folder through varietal screening of rice
}

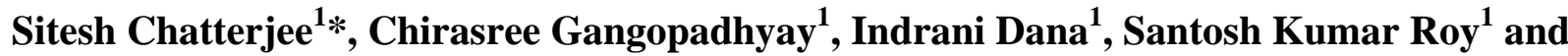 \\ Palash Mondal ${ }^{2}$
}

${ }^{1}$ Rice Research Station, Government of West Bengal, Department of Agriculture, Chinsurah (R.S.) - 712 102, Hooghly, West Bengal, India

${ }^{2}$ Department of Agricultural Entomology, Palli Siksha Bhavana, Visva- Bharati, Sriniketan - 731236, Birbhum, West Bengal, India

*Corresponding Author: sitesh.chatt@gmail.com

\begin{abstract}
Rice plant is attacked by many insect-pests of which yellow stem borer (dead heart at vegetative stage and white ear head at reproductive stage) and leaf folder are considered as prime devastator, responsible for major economic loss. To combat this problem, resistant varieties of rice are required for better production as well as better productivity. Host plant resistance is very much effective in integrated pest management (IPM) system, where negligible pesticidal hazard is present as well as environmental safety, low cost farming by without or minimum pesticide application and proper identification of resistant varieties for selection as parent in crossing programme to develop resistant varieties in future. The 78 rice varieties were screened out against Scirpophaga incertulas (yellow stem borer) and Cnaphalocrocis medinalis (rice leaf folder) of rice during Kharif, 2010-2012 at Rice Research Station, Chinsurah, Hooghly, under Government of West Bengal. The experiment was carried out to determine the level of resistance in early, mid-early, medium and late duration rice varieties, and shallow and semi-deep rice varieties. The pest infestation level was determined by counting dead heart, white ear head and damaged/folded leaves. The experimental results revealed that the early duration variety viz. Narendra 97 and IR 50, the mid-early duration variety i.e. IR 64 and IET 17904 proved resistant against both yellow stem borer (dead heart) and leaf folder. The medium duration variety, Ranjit was highly resistant against both yellow stem borer (dead heart) and leaf folder, and the variety, Pratiksha showed a fair degree of resistance against both yellow stem borer and leaf folder; while Jarava, the late duration variety exhibited high degree resistance against yellow stem borer (dead heart and white ear head). Besides, the varieties, Sashi and Giri recorded very low level of infestation of both lepidopteran pests while shallow and semi-deep variety such as Sashi was also considered resistant against the noxious pests.
\end{abstract}

Keywords: Host plant resistance, Varietal resistance, Yellow stem borer, Scirpophaga incertulas, Leaf folder, Cnaphalocrocis medinalis.

\section{INTRODUCTION}

Globally, the country India ranks second in terms of area of cultivation (about 44.6 million hectares) and production (104.32 million tonnes) under rice (Oryza sativa L.). The potential to yield is dented due to a lack of inbuilt resistance to different biotic stresses as discernible in $\sim 1,000$ rice cultivars across the country (Chatterjee et al., 2020). India, the second-largest rice growing country has a production of 104.32 million tonnes and cultivation area of about 44.6 million hectares with an average productivity of 2.34 tonnes per hectare (Rajasekar \& Jeyakumar, 2014). The state West Bengal ranks first in the area of cultivation as well as production of rice in India. About $78 \%$ of the total area under rice in the state is concentrated under high and medium productivity groups, which accounts for nearly $84 \%$ of total production of rice in the state (Chatterjee et al., 2016). A critical analysis of the gap between the potential and actual yield of rice across the nation reveal that there are a several factors which act as yield constraints. Riceplant is subjected to attack by more than 100 species of insects, of which 20 species of economic importance cause 20-30\% yield losses every year (Chatterjee et al., 2017). Yellow stem borer (YSB: Scirpophaga incertulas Walker) and leaf folder (LF: Cnaphalocrocis medinalis Guenée) of rice are considered as prime devastators responsible for major economic loss (Chatterjee \& Mondal, 2014; Chatterjee et al., 2017).

The host plant resistance depends upon the relationship between the plant-feeding insects and their host plants (Painter, 1951) which enables plants to avoid, tolerate or recover from the effects of insectpest attack and this mechanism has been proved to be a successful tool to protect crops from insects attack (Felkl et al., 2005). Potential to yield is dented due to a lack of inbuilt resistance to different biotic stresses as discernible in $\sim 1,000$ rice cultivars across the country (Chatterjee et al., 2020). Plant genotypes, either due to environmental stress or genetic makeup, possess physiological and biochemical differences which alter the nutritional value (primary metabolites) for plant feeding 
insects (Kaltenbach et al., 1994; Misirlı et al., 2000; Siemens et al., 2002; Alvim et al., 2004). In some cases, the combined nutritional and allelochemical alterations either improve the quality of the host plant as a source of food and can therefore be considered favorable to herbivorous insects (Baur et al., 1996; Alvim et al., 2004) or make the quality of host plant as source of food unfavorable to phytophagous insects (Stadler et al., 2002). Islam \& Karim (1997) studied the leaf-folding behavior of Cnaphalocrocis medinalis and reported that the rice leaf blade morphology i.e. width, length, and toughness might play a vital role in resistance against Cnaphalocrocis medinalis. They concluded that longer and tougher leaf blades might also contribute to resistance. Host plant selection is mainly a behavioral process that is primarily regulated by chemoreception (Jeremy \& Szentesi, 2003). The identification of resistant/tolerant rice varieties will help breeders for future use in developing multiple resistant new breeding rice lines (Chatterjee et al., 2016). The introduction of novel germplasm in breeding programme is very much required to diversify the genetic base (Thompson et al., 1988). The genetic improvement depends upon the amount of genetic variability present in the population of any crop (Vivekanandan \& Subramanian, 1993). Genotypes that have diverse genetic background are very much helpful to obtain high heterotic response and transgressive segregants for future breeding programme (Verma et al., 2004). The objective of the present research work is to assess the level of insect-pest tolerance as well as host plant resistance individually and multiple resistance against yellow stem borer and rice leaf folder under present climatic condition.

\section{MATERIALS AND METHODS}

The different categories of rice varieties viz. early duration, mid-early duration, medium duration, late duration and shallow and semi-deep rice (Table 1) were screened out against yellow stem borer and leaf folder during Kharif, 20102012 at Rice Research Station, Chinsurah, Hooghly, West Bengal situated at $88^{\circ} 24^{\prime}$ E longitude and $22^{\circ} 52^{\prime} \mathrm{N}$ latitude with an altitude of $8.62 \mathrm{~m}$ amsl in the alluvial zone of West Bengal, with sub-humid and sub-tropical climate. The experiment was conducted to find out the reaction of rice varieties (Table 1) against yellow stem borer and leaf folder in Kharif season. The five categories of rice varieties were transplanted in two rows of ten hills each with one skip row between entries with spacing of $20 \times 15 \mathrm{~cm}^{2}$ (row to row and plant to plant) @ single seedling per hill. The state recommended inorganic fertilizers were applied as $\mathrm{N}: \mathrm{P}_{2} \mathrm{O}_{5}: \mathrm{K}_{2} \mathrm{O} @$ 80:40:40. All the recommended agronomic package of practices were adopted during the experimentation in field. No plant protection measure i.e. no insecticidal treatment was done to maintain an optimum population pressure of target insect-pest on the field crop. The level of target insectpest infestation was determined by counting the proportion of affected hills showing dead heart, white ear head and folded leaves from ten numbers of hills of each variety. The observations were noticed on total tillers and dead heart by yellow stem borer and total leaves and folded leaves by rice leaf folder at the active tillering stage of the crop while, at pre-harvest stage the total panicle bearing tiller and white ear head by yellow stem borer from randomly selected ten hills of each variety.

Table 1. Categories of rice varieties for field screening against rice insect-pests.

\begin{tabular}{llr}
\hline Category & Name of rice varieties tested & $\begin{array}{r}\text { Number of } \\
\text { variety tested }\end{array}$ \\
\hline $\begin{array}{l}\text { Early duration } \\
\text { (upto 110 days) }\end{array}$ & Heera, Khanika, Pravat, Gotra Bidhan 1, Narendra 97, Annada, IR 50, Anjali, Rasi & 9 \\
$\begin{array}{l}\text { Mid-early duration } \\
(110-130 \text { days) }\end{array}$ & MTU 1010, Shatabdi, Khitish, Lalat, Ratna, IET 17904, IR 36, IR 64, IR 64 Sub 1, Nidhi, & 17 \\
$\begin{array}{l}\text { Medium duration } \\
(130-140 \text { days) }\end{array}$ & Kunti, Jaya, Vikramarya, Ajaya, Sasyasree, Samba Mashuri, Improved Samba Mashuri, & 13 \\
$\begin{array}{l}\text { Late duration } \\
\text { Pratiksha, Tapaswini, Vikash, Koushlya, Ranjit, Nona Bokhra }\end{array}$ & Swarna, Giri, Sashi, Swarnadhan, Nona Bokhra, NDR 8002, Mashuri, CR 1009, Patnai 23, & 12 \\
$\begin{array}{l}\text { Shallow and } \\
\text { semideep low land } \\
\text { rice }\end{array}$ & PR 113, Jarava, Kanak & Samba Mashuri Sub-1, Swarna Sub-1, Giri, Sashi, Dinesh, Mandira, Purnendu, Savitri, \\
\hline
\end{tabular}

\section{RESULTS AND DISCUSSION}

Several scientists have screened out many rice lines/entries/genotypes/varieties against different insect-pests of rice and they have identified many resistant/tolerant lines/entries/genotypes/varieties. In this experiment, the authors recorded the multiple resistant of different categories rice varieties against yellow stem borer (for per cent dead heart and white ear head) and rice leaf folder (for per cent folded leaves by rice leaf folder).

\section{Screening of early duration rice}

The results on screening of early duration rice varieties against Scirpophaga incertulas and Cnaphalocrocis medinalis revealed that the lowest dead heart infestation was discernible in Narendra 97 (2.08, 4.35 and 3.09\%, respectively) during 2010, 2011 and 2012 followed by Annada (4.63\%) and IR 50 (5.39\%) in 2010, IR 50 (5.88\%) and 
Pravat (6.33\%) in 2011 and Gotra selection 1 (4.34\%) and IR 50 (4.49\%) in 2012 (Table 2). The three years mean data showed that the minimum per cent dead heart was recorded in Narendra 97 (3.17\%) followed by IR $50(5.25 \%)$ and Annada (5.65\%). During 2010 and 2011 the lowest white ear head was recorded in Heera (3.30 and 2.00\%) followed by Narendra 97 (3.41\%) and Anjali (4.09\%) in 2010, and Gotra selection 1 (4.55\%) and Khanika (4.64\%) in 2011. Whereas the minimum white heads was recorded in Anjali (3.13\%), Gotra selection 1 (3.60\%) and Khanika (3.77\%) in 2012. The three years consecutive mean data indicated that the lowest per cent white heads was found in Heera (3.42\%) followed by Khanika (4.24\%) and Anjali (4.40\%). The minimum leaf folder infestation was discernible in Pravat (0.85\%), Narendra $97(1.04 \%)$ and Rasi $(1.11 \%)$ in 2010 and in IR $50(0.52 \%)$, Narendra $97(0.77 \%)$ and Pravat (1.25\%) during 2011 and in Annada (1.19\%), Pravat (1.21\%) and Narendra 97 (1.27\%) during 2012. Again, the three years mean data showed that poor leaf folder infestation was discernible in Narendra 97 (1.03\%) followed by Pravat $(1.10 \%)$ and IR $50(1.22 \%)$. Therefore, it was concluded that the early duration rice variety, Narendra 97 and IR 50 may be considered as resistant against both yellow stem borer (dead heart) and leaf folder.

Table 2. Screening of early duration (upto 110 Days) rice against yellow stem borer (Scirpophaga incertulas Walker) and leaf folder (Cnaphalocrocis Medinalis Guenée.).

\begin{tabular}{|c|c|c|c|c|c|c|c|c|c|c|c|c|}
\hline \multirow[t]{2}{*}{ Variety } & \multicolumn{3}{|c|}{ DH\% } & \multirow{2}{*}{$\begin{array}{l}\text { Mean } \\
\text { DH\% }\end{array}$} & \multicolumn{3}{|c|}{ WE\% } & \multirow{2}{*}{$\begin{array}{r}\text { Mean } \\
\text { WE\% }\end{array}$} & \multicolumn{3}{|c|}{ LF\% } & \multirow{2}{*}{$\begin{array}{l}\text { Mean } \\
\text { LF\% }\end{array}$} \\
\hline & 1 year & 2 year & 3 year & & 1 year & 2 year & 3 year & & 1 year & 2 year & 3 year & \\
\hline Heera & 9.21 & 8.20 & 6.10 & 7.84 & 3.30 & 2.00 & 4.95 & 3.42 & 2.60 & 2.19 & 1.68 & 2.16 \\
\hline Khanika & 9.82 & 9.52 & 8 & 9.41 & 4.30 & 4.64 & 3.77 & 4.24 & 3.24 & 3.18 & 1.47 & 2.63 \\
\hline Pravat & 6.81 & 6.33 & 4. & 6.00 & 5.76 & 6.67 & 5.22 & 5.88 & 0.85 & 1.25 & 1. & 1.10 \\
\hline Gotr: & 7.01 & 6.52 & 4. & 5.96 & 6.98 & 4.55 & 3. & 5.04 & 4.98 & 2.66 & 3. & 3.63 \\
\hline Nare & 2.08 & 4.35 & 3. & 3.17 & 3.41 & 6.41 & 4. & 4.84 & 1.04 & 0.77 & 1. & 1.03 \\
\hline Annc & 4.6 & 38 & & 5.65 & 6.42 & 7.39 & & 6.37 & 2.29 & 2.12 & 1.1 & 1.87 \\
\hline IR 5 & 5.39 & 5.88 & 4. & 5.25 & 6.03 & 7.62 & 4. & 5.95 & 1.75 & 0.52 & 1.40 & 1.22 \\
\hline Anjal & 9.30 & 10.42 & & 9.29 & 4.09 & 5.97 & 3.13 & 4.40 & 3.48 & 2.32 & 2.30 & 2.70 \\
\hline Rasi & 12.49 & 15.29 & 11.59 & 13.12 & 5.79 & 5.15 & 4.12 & 5.02 & 1.11 & 1.83 & 1.94 & 1.63 \\
\hline
\end{tabular}

\section{Screening of mid early duration rice}

The results on the screening of mid early duration rice varieties against Scirpophaga incertulas and Cnaphalocrocis medinalis revealed that the lowest dead heart incidence in mid early duration rice varieties was observed in IET 17904 (1.90 and 1.93\%) during 2010 and 2011 followed by Ratna (3.36\%) and Shatabdi (3.40\%) in 2010 and IR 64 (3.75\%) and Ratna (4.05\%) in 2011 (Table 3). The third-year screening result revealed that the lowest per cent of dead heart was observed in Triguna (2.56\%) followed by IET $17904(2.60 \%)$ and Narendra $359(3.61 \%)$. Over the three years mean data, revealed the minimum per cent of dead heart in IET 17904 (2.14\%), Ratna (3.69\%), IR 64 and Triguna (both $4.02 \%)$. The lowest white ear heads was discernible in KMR 3 (0.65 and 1.23\%) followed by Nidhi $(0.68$ and $1.28 \%)$ during 2010 and 2011, respectively followed by Narendra 359 (1.00\%) during 2010 and Khitish $(2.03 \%)$ in 2011. Whereas during 2012, the minimum incidence of white ear head was recorded in Nidhi $(1.00 \%)$, KMR $3(1.08 \%)$ and Narendra $359(2.25 \%)$. The three years mean data indicated that the lowest white heads was discernible in both Nidhi and KMR $3(0.99 \%)$ followed by Narendra $359(2.16 \%)$ and Khitish $(2.41 \%)$. The lowest leaf folder incidence was observed in IR $64(0.88 \%)$, IET $17904(0.61 \%)$ and MTU $1010(0.56 \%)$ during all the cropping seasons followed by Mohan (1.18\%) and MTU 1010 (1.33\%) in 2010, MTU 1010 (1.30\%) and Mohan (1.57\%) in 2011 and Lalat

Table 3. Screening of mid-early duration (110 to 130 days) rice against yellow stem borer (Scirpophaga incertulas Walker) and leaf folder (Cnaphalocrocis Medinalis Guenée.).

\begin{tabular}{|c|c|c|c|c|c|c|c|c|c|c|c|c|}
\hline \multirow[t]{2}{*}{ Variety } & \multicolumn{3}{|c|}{ DH\% } & \multirow{2}{*}{$\begin{array}{l}\text { Mean } \\
\text { DH\% }\end{array}$} & \multicolumn{3}{|c|}{ WE\% } & \multirow{2}{*}{$\begin{array}{l}\text { Mean } \\
\text { WE\% }\end{array}$} & \multicolumn{3}{|c|}{ LF\% } & \multirow{2}{*}{$\begin{array}{c}\text { Mean } \\
\text { LF\% }\end{array}$} \\
\hline & 1 year & 2 year & 3 year & & 1 year & 2 year & 3 year & & 1 year & 2 year & 3 year & \\
\hline MTU 1010 & 14.00 & 16.09 & 13.40 & 14.50 & 6.15 & 7.26 & 6.39 & 6.60 & 1.33 & 1.30 & 0.56 & 1.06 \\
\hline Shatabdi & 3.40 & 4.39 & 5.20 & 4.33 & 4.08 & 8.92 & 5.43 & 6.14 & 2.38 & 2.06 & 2.04 & 2.16 \\
\hline Khitish & 3.83 & 6.14 & 6.32 & 5.43 & 1.31 & 2.03 & 3.90 & 2.41 & 1.94 & 2.14 & 1.26 & 1.78 \\
\hline Lalat & 10.38 & 9.18 & 8.84 & 9.47 & 2.87 & 4.70 & 3.68 & 3.75 & 1.67 & 2.04 & 0.96 & 1.56 \\
\hline Ratna & 3.36 & 4.05 & 3.66 & 3.69 & 6.61 & 9.81 & 5.22 & 7.21 & 2.88 & 2.14 & 1.14 & 2.05 \\
\hline IET 17904 & 1.90 & 1.93 & 2.60 & 2.14 & 6.19 & 4.24 & 4.97 & 5.13 & 1.76 & 0.61 & 1.52 & 1.30 \\
\hline IR 36 & 3.70 & 5.00 & 4.00 & 4.23 & 1.72 & 2.14 & 3.45 & 2.44 & 2.78 & 1.71 & 1.00 & 1.83 \\
\hline IR 64 & 3.51 & 3.75 & 4.80 & 4.02 & 3.38 & 2.79 & 3.95 & 3.37 & 0.88 & 1.76 & 1.20 & 1.28 \\
\hline IR 64 Sub 1 & 17.07 & 13.27 & 13.73 & 14.69 & 5.21 & 5.18 & 3.30 & 4.56 & 4.88 & 4.52 & 3.70 & 4.37 \\
\hline Nidhi & 5.57 & 7.46 & 5.14 & 6.06 & 0.68 & 1.28 & 1.00 & 0.99 & 3.57 & 2.98 & 2.55 & 3.03 \\
\hline PR 106 & 4.12 & 6.85 & 5.45 & 5.47 & 8.22 & 9.41 & 9.65 & 9.09 & 3.28 & 2.20 & 1.59 & 2.36 \\
\hline Narendra 359 & 7.14 & 6.30 & 3.61 & 5.68 & 1.00 & 3.22 & 2.25 & 2.16 & 6.07 & 4.66 & 5.72 & 5.48 \\
\hline $\mathrm{TN} 1$ & 7.48 & 9.24 & 10.66 & 9.13 & 5.72 & 6.38 & 8.03 & 6.71 & 6.54 & 4.80 & 5.41 & 5.58 \\
\hline PNR 519 & 5.00 & 7.35 & 4.03 & 5.46 & 4.02 & 6.67 & 3.37 & 4.69 & 7.50 & 5.92 & 4.22 & 5.88 \\
\hline Triguna & 4.82 & 4.69 & 2.56 & 4.02 & 4.72 & 4.39 & 4.44 & 4.52 & 4.23 & 3.69 & 3.84 & 3.92 \\
\hline KMR 3 & 5.97 & 4.03 & 6.79 & 5.60 & 0.65 & 1.23 & 1.08 & 0.99 & 1.49 & 2.69 & 2.91 & 2.36 \\
\hline Mohan & 8.71 & 11.50 & 12.60 & 10.94 & 4.12 & 6.03 & 3.90 & 4.68 & 1.18 & 1.57 & 1.77 & 1.51 \\
\hline
\end{tabular}


$(0.96 \%)$ and IR $36(1.00 \%)$ in 2012 . The three years mean data indicated the lowest leaf folder infestation in MTU 1010 $(1.06 \%)$ followed by IR $64(1.28 \%)$ and IET $17904(1.30 \%)$. Among the mid-early duration rice varieties, IR 64 and IET 17904 showed resistant against both yellow stem borer (dead heart) and leaf folder.

\section{Screening of medium duration rice}

Screening on the medium duration rice varieties against Scirpophaga incertulas and Cnaphalocrocis medinalis showed the lowest per cent dead heart in Ranjit (2.88 and 5.13\%) during 2010 and 2011 followed by Sasyasree (3.45\%) and Vikash (5.33\%) in 2010 and Vikash (6.50\%) and Sasyasree (6.86\%) during 2011(Table 4). Whereas in 2012, the lowest incidence was noticed in Sasyasree (4.09\%) followed by Ranjit (6.83\%) and Vikash (7.50\%). Consecutive three years mean data indicated that the lowest dead heart incidence was discernible in Sasyasree (4.80\%) followed by Ranjit (4.95\%) and Vikash (6.44\%). During 2010, 2011 and 2012, the lowest white heads was noticed in Samba Mashuri $(0.88,1.22$ and $1.16 \%$, respectively) followed by Partiksha (1.90\%) and Tapaswini (3.00\%) in 2010 and Pratiksha $(1.38 \%)$ and Ranjit $(1.63 \%)$ in 2011 and Koushlya (2.04\%) and Pratiksha (2.17\%) in 2012. The three years consecutive mean data indicated that the lowest white head incidence was observed in Samba Mashuri (1.16\%) followed by Pratiksha (1.82\%) and Ranjit (2.37\%). The lowest leaf folder damage was found in Koushlya (1.80\%) followed by Kunti $(1.98 \%)$ and Improved Samba Mashuri (2.84\%) in 2010 and in Tapaswini (1.53\%) followed by Improved Samba Mashuri (1.66\%) and Pratiksha (1.87\%) in 2011 and in Pratiksha (1.30\%) followed by Koushlya (1.49\%) and Nona Bokhra (1.61\%) in 2012. Interestingly, three years mean data indicated that the lowest infestation of leaf folder was found in Koushlya (1.84\%) followed by Improved Samba Mashuri $(2.11 \%)$ and Pratiksha (2.37\%). The medium duration rice variety, Ranjit was highly resistant while Pratiksha showed fair degree of resistant but lesser to the variety, Ranjit against both yellow stem borer and leaf folder.

Table 4. Screening of medium duration (130 to 140 days) rice against yellow stem borer (Scirpophaga incertulas Walker) and leaf folder (Cnaphalocrocis Medinalis Guenée.).

\begin{tabular}{|c|c|c|c|c|c|c|c|c|c|c|c|c|}
\hline \multirow[t]{2}{*}{ Variety } & \multicolumn{3}{|c|}{ DH\% } & \multirow{2}{*}{$\begin{array}{l}\text { Mean } \\
\text { DH\% }\end{array}$} & \multicolumn{3}{|c|}{ WE\% } & \multirow{2}{*}{$\begin{array}{l}\text { Mean } \\
\text { WE\% }\end{array}$} & \multicolumn{3}{|c|}{ LF\% } & \multirow{2}{*}{$\begin{array}{r}\text { Mean } \\
\text { LF\% }\end{array}$} \\
\hline & 1 year & 2 year & 3 year & & 1 year & 2 year & 3 year & & 1 year & 2 year & 3 year & \\
\hline Kunti & 11.88 & 13.25 & 11.02 & 12.05 & 7.92 & 9.91 & 8.65 & 8.83 & 1.98 & 2.01 & 3.94 & 2.64 \\
\hline Jaya & 10.64 & 11.02 & 9.04 & 10.23 & 5.83 & 8.19 & 6.38 & 6.80 & 6.38 & 4.94 & 5.86 & 5.73 \\
\hline Vikramarya & 10.67 & 15.79 & 11.92 & 12.79 & 8.08 & 8.63 & 9.35 & 8.69 & 5.33 & 5.70 & 5.19 & 5.41 \\
\hline Ajaya & 12.99 & 13.26 & 12.07 & 12.77 & 4.25 & 6.79 & 6.98 & 6.01 & 4.19 & 3.45 & 2.77 & 3.47 \\
\hline Sasyasree & 3.45 & 6.86 & 4.09 & 4.80 & 8.00 & 7.78 & 3.09 & 6.29 & 3.48 & 2.44 & 3.89 & 3.27 \\
\hline Samba Mashuri & 6.22 & 7.89 & 8.00 & 7.37 & 0.88 & 1.39 & 1.22 & 1.16 & 3.67 & 2.34 & 2.40 & 2.80 \\
\hline $\begin{array}{l}\text { Improved Samba } \\
\text { Mashuri }\end{array}$ & 9.68 & 7.48 & 8.94 & 8.70 & 2.06 & 4.09 & 3.09 & 3.08 & 2.84 & 1.66 & 1.82 & 2.11 \\
\hline Pratik & 7.79 & 8.42 & 9. & 8. & 1.90 & 1.38 & 2.17 & 1.8 & 3.93 & 1.87 & 1.30 & 2.37 \\
\hline Tapa & 6.80 & 9.48 & 8.47 & 8.25 & 3.00 & 6.53 & 4.55 & 4.69 & 3.81 & 1.53 & 2.11 & 2.48 \\
\hline Vikas & 5.33 & 6.50 & 7.50 & 6. & 5.67 & 9.54 & 8.75 & 7.99 & 3.33 & 2.76 & 1.66 & 2.58 \\
\hline Koushlya & 13.80 & 11.00 & 10.25 & 11. & 3.06 & 6.76 & 2.04 & 3.95 & 1.80 & 2.22 & 1.49 & 1.84 \\
\hline Ran & 2.88 & 5.13 & & 4.95 & 3.06 & 1.63 & 2.41 & 2.37 & 3.63 & 3.68 & 2.35 & 3.22 \\
\hline Nona Bokhra & 7.52 & 7.27 & 10.48 & 8.42 & 7.14 & 8.33 & 8.04 & 7.84 & 3.01 & 2.57 & 1.61 & 2.40 \\
\hline
\end{tabular}

\section{Screening of late duration rice}

Among the late duration rice varieties, the lowest per cent of dead heart was observed in Kanak (2.37 and $4.76 \%)$ in 2010 and 2011 followed by NDR 8002 (5.13\%) and Mashuri (5.41\%) in 2010 and Mashuri (5.30\%) and NDR 8002 $(5.93 \%)$ in 2011 (Table 5). In 2012, the lowest dead heart incidence was observed in NDR 8002 (4.89\%) followed by Kanak (5.21\%) and PR $113(6.77 \%)$. The three years mean on dead heart incidence indicated that the lowest infestation of dead heart in Kanak (4.11\%) followed by NDR $8002(5.31 \%)$ and Mashuri (6.20\%). The lowest whiteheads was

Table 5. Screening of late duration (more than 140 days) rice against yellow stem borer (Scirpophaga incertulas Walker) and leaf folder (Cnaphalocrocis Medinalis Guenée.).

\begin{tabular}{|c|c|c|c|c|c|c|c|c|c|c|c|c|}
\hline \multirow[t]{2}{*}{ Variety } & \multicolumn{3}{|c|}{ DH\% } & \multirow{2}{*}{$\begin{array}{l}\text { Mean } \\
\text { DH\% }\end{array}$} & \multicolumn{3}{|c|}{ WE\% } & \multirow{2}{*}{$\begin{array}{r}\text { Mean } \\
\text { WE\% } \\
\end{array}$} & \multicolumn{3}{|c|}{ LF\% } & \multirow{2}{*}{$\begin{array}{l}\text { Mean } \\
\text { LF\% }\end{array}$} \\
\hline & 1 year & 2 year & 3 year & & 1 year & 2 year & 3 year & & 1 year & 2 year & 3 year & \\
\hline Swarna & 16.13 & 11.11 & 11.87 & 13.04 & 9.72 & 8.13 & 10.50 & 9.45 & 5.06 & 6.67 & 5.37 & 5.70 \\
\hline Giri & 7.20 & 11.74 & 8.69 & 9.21 & 1.61 & 2.54 & 1.00 & 1.72 & 2.85 & 1.74 & 1.73 & 2.11 \\
\hline Sashi & 5.50 & 6.36 & 6.80 & 6.22 & 0.77 & 1.87 & 0.90 & 1.18 & 1.50 & 1.42 & 50 & 1.51 \\
\hline Swarnadhan & 9.56 & 12.80 & 9.64 & 10.67 & 2.06 & 3.00 & 4.50 & 3.19 & 6.94 & 4.17 & 75 & 5.29 \\
\hline Nona Bokhra & 7.52 & 7.27 & 10.48 & 8.42 & 7.14 & 8.33 & 8.04 & 7.84 & 3.01 & 2.57 & 1.61 & 2.40 \\
\hline NDR 8002 & 5.13 & 5.93 & 4.89 & 5.31 & 8.35 & 5.13 & 5.93 & 6.47 & 2.75 & 2.12 & 9.14 & 4.67 \\
\hline Mashuri & 5.41 & 5.30 & 7.90 & 6.20 & 3.60 & 4.96 & 4.00 & 4.19 & 5.41 & 4.88 & 5.22 & 5.17 \\
\hline CR 1009 & 6.60 & 8.67 & 10.37 & 8.55 & 5.26 & 3.64 & 4.01 & 4.30 & 4.61 & 2.82 & 3.06 & 3.50 \\
\hline Patnai 23 & 21.28 & 18.11 & 16.79 & 18.73 & 4.12 & 3.70 & 5.95 & 4.59 & 4.26 & 2.93 & 1.94 & 3.04 \\
\hline PR 113 & 9.88 & 7.86 & 6.77 & 8.17 & 14.19 & 19.29 & 16.19 & 16.56 & 4.81 & 2.33 & 2.75 & 3.30 \\
\hline Jarava & 13.08 & 11.22 & 10.10 & 11.47 & 0.90 & 2.20 & 2.88 & 1.99 & 3.61 & 2.52 & 2.52 & 2.88 \\
\hline Kanak & 2.37 & 4.76 & 5.21 & 4.11 & 3.52 & 2.50 & 1.95 & 2.66 & 4.27 & 3.81 & 3.91 & 4.00 \\
\hline
\end{tabular}


discernible in Sashi in consecutive three years $(0.77,1.87$ and $0.90 \%$, respectively) followed by Jarava $(0.90 \%)$ and Giri $(1.61 \%)$ in 2010 and Jarava (2.20\%) and Kanak (2.50\%) in 2011 and Giri (1.00\%) and Kanak (1.95\%) in 2012. The three years mean white head infestation indicated that Sashi (1.18\%) followed by Giri (1.72\%) and Jarava (1.99\%) showed the low level of infestation. The lowest leaf infestation was observed in Sashi (1.50, 1.42 and 1.60\%, respectively) during 2010-2012 followed by NDR 8002 (2.75\%) and Giri (2.85\%) in 2010 and Giri (1.73\%) and NDR $8002(2.12 \%)$ in 2011 and Nona Bokhra (1.61\%) and Giri (1.73\%) in 2012. The mean data showed that the lowest leaf folder incidence was found in Sashi (1.51\%) followed by Giri $(2.11 \%)$ and Nona Bokhra (2.40\%). Jarava, the late duration variety had strong resistance against yellow stem borer and both the varieties, Sashi and Giri were resistant against yellow stem borer (white ear head) and leaf folder.

\section{Screening of shallow and semi-deep rice}

The shallow and semi-deep rice, Sabita $(4.80 \%)$ followed by Pooja $(4.82 \%)$ and Biraj $(5.36 \%)$ showed lower infestation of dead heart in 2010 (Table 6). In 2011, the minimum dead heart incidence was observed in Biraj (4.09\%), Pooja (5.11\%) and Sashi (6.36\%), accordingly. Whereas in 2012, the lowest dead heart was observed in Niraja (6.25\%) followed by Pooja $(6.54 \%)$ and Sashi $(6.80 \%)$. The three years consecutive mean on dead heart incidence indicated that the lowest infestation was found in Pooja (5.49\%) followed by Biraj (5.57\%) and Sashi (6.22\%). The lowest white ear head incidence was noticed in Sashi $(0.77 \%)$ followed by Jalamagna (1.50\%) and Samba Mashuri Sub-1 (1.51\%) in 2010 and the lowest infestationwas recorded in Samba Mashuri Sub-1 (1.33 and 0.70\%, respectively) during 2011 and 2012 followed by Sashi (1.87\%), Purnendu (1.96\%) in 2011 and Sashi (0.90\%), Giri (1.00\%) in 2012. The three years mean data indicated that the lowest white heads was discernible in both Samba Mashuri Sub-1 and Sashi (1.18\%) followed by Giri (1.72\%), Jalamagna (2.09\%). In 2010, the minimum leaf folder incidence was recorded in Sashi (1.50\%) Mandira (1.61\%) and Sunil (1.72\%). The lowest folded leaf was observed in Bhudeb (1.31\%) followed by Sashi $(1.42 \%)$ and Niraja (1.67\%) in 2011. Whereas in 2012, the minimum incidence was noticed in Purnendu (1.37\%), Sashi (1.60\%), Bhudeb and Biraj (1.61\%). The three years mean data indicated that the lowest folded leaves was discernible in Sashi (1.51\%) followed by Bhudeb (1.74\%) and Sunil (1.94\%). It may be concluded that among the shallow and semi-deep rice varieties, Sashi was highly resistant against both yellow stem borer and leaf folder.

Table 6. Screening of shallow and semi-deep low land rice against yellow stem borer (Scirpophaga incertulas Walker) and leaf folder (Cnaphalocrocis Medinalis Guenée.).

\begin{tabular}{|c|c|c|c|c|c|c|c|c|c|c|c|c|}
\hline \multirow[t]{2}{*}{ Variety } & \multicolumn{3}{|c|}{ DH\% } & \multirow{2}{*}{$\begin{array}{l}\text { Mean } \\
\text { DH\% }\end{array}$} & \multicolumn{3}{|c|}{ WE\% } & \multirow{2}{*}{$\begin{array}{l}\text { Mean } \\
\text { WE\% }\end{array}$} & \multicolumn{3}{|c|}{ LF\% } & \multirow{2}{*}{$\begin{array}{l}\text { Mean } \\
\text { LF\% }\end{array}$} \\
\hline & 1 year & 2 year & 3 year & & 1 year & 2 year & 3 year & & 1 year & 2 year & 3 year & \\
\hline $\begin{array}{l}\text { Samba Mashuri } \\
\text { Sub-1 }\end{array}$ & 5.50 & 6.73 & 7.16 & 6.46 & 1.51 & 1.33 & 0.70 & 1.18 & 3.02 & 3.85 & 2.33 & 3.07 \\
\hline Swarna Sub-1 & 12.85 & 11.15 & 7.50 & 10.50 & 4.70 & 3.90 & 5.77 & 4.79 & 5.04 & 4.35 & 4.87 & 4.75 \\
\hline Giri & 7.20 & 11.74 & 8.69 & 9.21 & 1.61 & 2.54 & 1.00 & 1.72 & 2.85 & 1.74 & 1.73 & 2.11 \\
\hline Sashi & 5.50 & 6.36 & 6.80 & 6.22 & 0.77 & 1.87 & 0.90 & 1.18 & 1.50 & 1.42 & 1.60 & 1.51 \\
\hline Dinesh & 8.20 & 6.42 & 9.81 & 8.14 & 4.21 & 3.48 & 2.15 & 3.28 & 2.20 & 3.83 & 1.77 & 2.60 \\
\hline Mandira & 11.29 & 10.34 & 9.75 & 10.46 & 3.07 & 3.28 & 5.89 & 4.08 & 1.61 & 2.76 & 2.03 & 2.13 \\
\hline Purnendu & 8.93 & 7.83 & 7.87 & 8.21 & 3.41 & 1.96 & 3.73 & 3.03 & 3.36 & 2.39 & 1.37 & 2.37 \\
\hline Savitri & 13.33 & 10.00 & 10.07 & 11.13 & 2.98 & 2.29 & 5.20 & 3.49 & 4.44 & 3.11 & 3.35 & 3.63 \\
\hline Sabita & 4.80 & 8.43 & 7.37 & 6.87 & 6.08 & 4.85 & 4.55 & 5.16 & 3.40 & 2.35 & 2.66 & 2.80 \\
\hline Bhagarathi & 7.46 & 9.00 & 8.33 & 8.26 & 3.90 & 3.92 & 6.73 & 4.85 & 2.99 & 4.59 & 3.51 & 3.70 \\
\hline Bhudeb & 8.90 & 10.78 & 9.67 & 9.78 & 3.88 & 7.92 & 4.70 & 5.50 & 2.30 & 1.31 & 1.61 & 1.74 \\
\hline Biraj & 5.36 & 4.09 & 7.25 & 5.57 & 3.27 & 2.97 & 4.80 & 3. & 3.57 & 3.14 & 1.61 & 2.77 \\
\hline Gola & 6.29 & 9.24 & 8.47 & 8.00 & 3.40 & 4.54 & 5.61 & 4. & 3.29 & 2.12 & 1.69 & 2.37 \\
\hline Nalin & 11.89 & 10.41 & 9.91 & 10.74 & 4. & 2.02 & 3.94 & 3. & 4.44 & 2.26 & 3.44 & 3.38 \\
\hline Shalib & 6.40 & 8.77 & 7.69 & & 3. & 5.77 & 4.30 & 4. & 4.59 & 4.04 & 2.85 & 3.83 \\
\hline Ambika & 9.66 & 12.79 & 8.94 & 10.46 & 3.49 & 4.15 & 5.00 & 4.21 & 3.77 & 4.59 & 3.03 & 3.80 \\
\hline Jalamagna & 10.53 & 14.46 & 9.48 & 11.49 & 1.50 & 2.73 & 2.04 & 2.09 & 3.77 & 2.92 & 3.44 & 3.38 \\
\hline Jallahiri & 16.82 & 21.43 & 17.89 & 18.71 & 3.62 & 5.00 & 3.33 & 3.98 & 5.61 & 3.79 & 3.94 & 4.45 \\
\hline Matla & 17.39 & 18.45 & 14.43 & 16.76 & 7.47 & 11.50 & 6.37 & 8.45 & 3.52 & 3.15 & 3.60 & 3.42 \\
\hline Niraja & 5.83 & 7.83 & 6.25 & 6.64 & 3.19 & 4.96 & 5.39 & 4.51 & 1.94 & 1.67 & 2.91 & 2.17 \\
\hline Pooja & 4.82 & 5.11 & 6.54 & 5.49 & 3.83 & 2.83 & 4.45 & 3.70 & 4.82 & 4.37 & 5.37 & 4.85 \\
\hline Hansheswari & 16.22 & 21.62 & 15.88 & 17.91 & 5.18 & 8.64 & 7.20 & 7.01 & 3.80 & 2.25 & 4.44 & 3.50 \\
\hline Rajdeep & 7.50 & 8.93 & 12.72 & 9.72 & 5.55 & 3.89 & 4.35 & 4.60 & 5.00 & 4.02 & 5.22 & 4.75 \\
\hline Jogen & 11.18 & 13.67 & 10.61 & 11.82 & 2.75 & 2.96 & 1.94 & 2.55 & 3.12 & 2.89 & 2.65 & 2.89 \\
\hline Sunil & 10.34 & 15.33 & 9.24 & 11.64 & 3.00 & 3.73 & 1.04 & 2.59 & 1.72 & 1.78 & 2.31 & 1.94 \\
\hline Amulya & 11.11 & 11.81 & 15.83 & 12.92 & 3.79 & 4.21 & 2.30 & 3.43 & 4.96 & 3.30 & 2.29 & 3.52 \\
\hline Mahananda & 9.16 & 11.54 & 10.46 & 10.39 & 11.20 & 17.05 & 13.19 & 13.81 & 3.11 & 2.70 & 2.88 & 2.90 \\
\hline
\end{tabular}

Balasubramanian et al. (2000) screened 178 advanced yield trial genotypes of rice for their reaction to insect pests under natural conditions as per Standard Evaluation System (SES) of IRRI, Philippines. The experiment results showed the rice genotypes, IET 15742 and IET 15072 against YSB and IET 16120 against rice leaf folder were found 
moderately resistant from out of 178 total genotypes. Singh et al. (2006) screened 53 rice cultivars against Scirpophaga incertulas under natural condition. Observations based on per cent damage incidence of YSB were recorded as the eighteen rice varieties were totally free from stem borer damage in terms of DH and WE. Thirty-one rice entries were screened against Scirpophaga incertulas, under field and greenhouse conditions by Dhuyo \& Soomro (2007). Field studies were conducted in West Bengal, India, during the 2010 Kharif season, to screen different rice cultivars against rice leaf folder (Cnaphalocrocis medinalis) and stem borer (Scirpophaga incertulas) and find out the tolerant and susceptible strains (Chatterjee et al., 2011).

\section{CONCLUSION}

Authors have tried to find out the multiple resistant rice varieties against yellow stem borer (dead heart and white ear head) and leaf folder which may be considered as host plant resistance to insect-pests of rice. The host plant resistance mechanism may be used as an effective, eco-friendly and economical method of pest control where no pesticide is required in the field. The early duration rice varieties viz. Narendra 97 and IR 50 mid-early duration variety viz. IR 64 and IET 17904 medium duration variety viz. Ranjit and Pratiksha late duration varieties viz. Jarava and Giri the and shallow and semi-deep variety Sashi showed different levels of resistance against yellow stem borer and leaf folder and can be recommended for cultivation where regular infestation of these pests was recorded.

\section{REFERENCES}

Alvim G.S.J., Collevatti R.G. \& Fernandes G.W. (2004). Effects of genetic variability and habitat of Qualeaparviflora (Vochysiaceae) on Herbivory by Free feeding and Gall-forming Insects. Annals of Botany, 94: 259-268.

Balasubramanianan V., Sadakathulla S., Subramanian M. \& Ramanathan S. (2000). Screening Rice entries of AICRIP in advanced yield trial for Resistance to Insect Pests of Rice. International Plant Resistance to Insects Newsletter, 26: 52.

Baur R., Birch A.N.E., Hopkins R.J., Griffiths D.W., Simmonds M.S.J. \& Städler E. (1996). Oviposition and chemosensory stimulation of the root flies Delia radicum and D. floralisin response to plant and leaf surface extracts from resistant and susceptible Brassica genotypes. Entomologia Experimentalis et Applicata, 78: 61-75.

Chatterjee S. \& Mondal P. (2014). Management of rice yellow stem borer, Scirpophaga incertulas Walker using some biorational insecticides. Journal of Biopesticides, 7 (supplement): 143-147.

Chatterjee S., Gangopadhyay C., Bandyopadhyay P., Bhowmick M.K., Roy S.K., Majumder A., Gathala M.K., Tanwar R.K., Singh S.P., Birah A. \& Chattopadhyay C. (2020). Input-based assessment on integrated pest management for transplanted rice (Oryza sativa) in India. Crop Protection, 141: 105444. [DOI: 10.1016/j.cropro.2020.105444]

Chatterjee S., Ghose M. \& Gangopadhyay C. (2016). Field screening of different rice entries against different insect-pests of rice during kharif season. International Journal of Agriculture, Environment and Biotechnology, 9(4): 667-671.

Chatterjee S., Mondal P., Dana I., Gangopadhyay C. \& Nayak U. (2017). Screening of rice genotypes for their resistance against yellow stem borer and leaf folder. SATSA Mukhaptra Annual Technical Issue, 21: 200-206.

Chatterjee S., Nayak U.S., Mandal P. \& Singh N.J. (2011). Screening of rice cultivars against rice leaf folder (Cnaphalocrocis medinalis) and rice stem borer (Scirpophaga incertulas) during kharif season in the new alluvial zone of West Bengal. Journal of Plant Protection and Environment, 8(1): 125-127.

Dhuyo A.R. \& Soomro N.M. (2007). The response of different rice varieties to infestation of yellow rice stem borer, Scirpophaga incertulas (Walk.) under field and green house conditions. Pakistan Entomology, 29: 27-32.

Felkl G., Jensen E.B., Kristiansen K. \& Andersen S.B. (2005). Tolerance and antibiosis resistance to cabbage root fly in vegetable Brassica species. Entomologia Experimentalis et Applicata, 116(1):65-71.

Islam Z. \& Karim A.N.M.R. (1997). Leaf folding behaviour of Cnaphalocrocis medinalis (Guenee) and Marasmia patnalis Bradley and the influence of rice leaf morphology on damage incidence. Crop Protection, 16: 215-220.

Jeremy T. \& Szentesi A. (2003). Evolutionary aspects of host plant specialisation - a study on bruchids (Coleoptera: Bruchidae). Oikos, 101: 196-204.

Kaltenbach E., Ernst H.D., Heller W. \& Sandermann H.J. (1994). Cross-induction of defensive phenylpropanoid pathways in parsley plants by ozone. Acta Horticulturae, 381: 192-198.

Misırlı A., Küden A., Demir G. \& Gülcan R. (2000). Determination of phenolic compounds in some almond hybrids varying in resistance to Pseudomonas amygdale. Report Project TOGTAG-1433, pp. 71-86.

Painter R. (1951). Insect resistance in crop plants. Mac Millan, New-York, pp. 168.

Rajasekar N. \& Jeyakumar P. (2014). Differential response of trifloxystrobin in combination with tebuconazole on growth, nutrient uptake and yield of rice (Oryza sativa L.). International Journal of Agriculture. Environment and Biotechnology, 6(1): 87-93.

Siemens D.H., Garner S.H., Mitchell-Olds T. \& Callaway R.M. (2002). Cost of defense in the context of plant competition: Brassica rapamay grow and defend. Ecology, 83: 505-517.

Singh R.B., Singh R.A., Dwivedi J.L. \& Chaudhary R.K. (2006). Reaction of different rice varieties/cultivars against leaf folder, Cnaphalocrocis medinalis Guen.and stem borer, Scirpophaga incertulas Walker under irrigated conditions. Journal of Plant Protection and Environment, 3: 4-16.

Stadler E. (2002). Plant chemical cues important for egg deposition by herbivorous insects. In: Hilker M. \& Meiners T. (eds.) Chemoecology of insect eggs and egg deposition. Blackwell, Oxford, pp. 171-197. 
Thompson J.A., Nelson R.L. \& Vodkin L.O. (1998). Identification of diverse soybean germplasm using RAPD markers. Crop Science, 38: 1348-55.

Verma O.P. \& Srivastava H.K. (2004). Productive association of quantitative traits in diverse ecotypes of rice (O.Sativa L.). Journal of Sustainable Agriculture, 25: 75-91.

Vivekanandan P. \& Subramanian S. (1993). Genetic divergence in rainfed rice. Oryza, 30: 60-62. 